\title{
The Dopamine Receptor D4 Gene 7-Repeat Allele Interacts with Parenting Quality to Predict Effortful Control in Four-Year-Old Children
}

\author{
Brad E. Sheese, ${ }^{1}$ Mary K. Rothbart, ${ }^{2}$ Pascale M. Voelker, ${ }^{2}$ and Michael I. Posner ${ }^{2}$ \\ ${ }^{1}$ Department of Psychology, Illinois Wesleyan University, 201 E. Beecher Strect, Bloomington, IL 61701, USA \\ ${ }^{2}$ Department of Psychology, University of Oregon, Straub Hall 1227 University of Oregon, Eugene, OR 97403, USA
}

Correspondence should be addressed to Michael I. Posner, mposner@uoregon.edu

Received 22 March 2012; Accepted 23 April 2012

Academic Editor: Andrew N. Meltzoff

Copyright (C) 2012 Brad E. Sheese et al. This is an open access article distributed under the Creative Commons Attribution License, which permits unrestricted use, distribution, and reproduction in any medium, provided the original work is properly cited.

\begin{abstract}
The dopamine receptor D4 gene (DRD4) 7-repeat allele has been found to interact with environmental factors such as parenting in children and peer attitudes in adults to influence aspects of behavior such as risk taking. We previously found that in toddlers, lower-quality parenting in combination with the 7-repeat allele of the DRD4 gene was associated with greater parent-reported Sensation Seeking (SS), but was unrelated to Effortful Control (EC). We now report findings from a followup assessment with the same sample of children showing that parenting quality interacts with the presence of the 7-repeat allele to predict EC in 3to 4 -year-old children. The change in these patterns of results may reflect the increased role of the executive attention network in older children and adults. However, due to the small sample size $(N=52)$ and the novelty of the results, these findings should be treated with caution and considered preliminary until they are replicated in an independent sample.
\end{abstract}

\section{Introduction}

Many studies suggest that the 7-repeat allele of the dopamine receptor D4 gene (DRD4) interacts with environmental factors to predict sensation seeking and externalizing behaviors in children and adults [1-5]. However, the mechanism through which DRD4 interacts with environmental factors remains unclear. One possibility is that DRD4 variations might influence these outcomes through the executive attention network that controls many forms of voluntary behavior [6]. In the current paper, we evaluate this hypothesis using data from a long-term longitudinal study of attention and temperament development in children. We review previously published results linking DRD4 and parenting to Sensation Seeking in toddlers and present new evidence linking DRD4 and parenting to Effortful Control (EC) in 3- to 4-year-old children.

1.1. DRD4 and Environmental Influences. Many studies argue for the hypothesis that variations in DRD4 alter a child's susceptibility to environmental factors $[2,3,7]$. A meta-analysis found that children with one or two copies of the DRD4 7-repeat allele may be more susceptible to both positive and negative environmental influences [8]. There is also evidence that the 7-repeat allele is undergoing positive selection in human evolution [9]. A possible explanation of positive selection is that increased susceptibility to environmental influences conferred by this variant might increase effectiveness of socialization, ultimately increasing the likelihood of reproduction [3]. There is further evidence that susceptibility to environmental influences continues in adults. Those who have the 7-repeat allele are more influenced in their alcohol consumption by their peers than those without this allele [5]. In adolescents, the presence of the 7-repeat allele interacts with the adolescent's number of friends to predict political ideology, with those having the 7-repeat and an environment with many friends showing a liberal tendency [10].

In a previously published study of 18 - to 21 -month-old children, we examined how parenting quality and DRD4 interact to predict two aspects of temperament [3]. We used a free-play observation in a laboratory setting to assess 
parenting quality. The first aspect was a measure of SS, which combined scales assessing high-intensity pleasure, activity level, and impulsivity. The second aspect was a measure of EC, which combined scales assessing attentional focusing, attentional shifting, and inhibitory control. We found a significant interaction predicting SS scores, such that higher quality of parenting was related to lower SS for children 18 to 21 months old with the 7-repeat allele but unrelated to SS for children without the 7-repeat allele. We found no evidence of either main effects or an interaction predicting EC.

Subsequently, we found that the control system used by toddlers at 18 to 21 months was not the executive system but rather the orienting system $[11,12]$. This was shown in two different ways. First, as measured by parent report, positive affect was positively related to children's skills in orienting attention, and Negative Affect was inversely related to parent-reported orienting. Second, the visual looking task that we had previously shown to be related to the control of affect during infancy [13] proved to be more closely related to the orienting network than to the executive network as measured by the Attention Network Test at the age of 3 to 4. This finding may relate to evidence that in childhood the executive and orienting networks appear to be more strongly interconnected than in adulthood [14]. Overall, the evidence suggests that the relation of the DRD4 7-repeat allele to EC may not be present at 18 to 21 months because the executive network related to EC has not yet been sufficiently connected to exercise control. In this paper we re-examine the relationship between parenting and EC at the age of 34. We test whether the 7-repeat allele and parenting quality measured at 18 to 21 months interact to predict EC at 4 years of age, when EC is a measure of self-regulation and is correlated with executive attention.

\section{Method}

The procedures in this experiment were approved by the Institutional Review Board of the University of Oregon that assured compliance with ethical considerations of the Helsinki Declaration. All parents signed informed consent forms that included their permission for publication of the overall results without identification of individuals.

2.1. Participants. Data for the current study are from an ongoing longitudinal study of the development of attention and temperament conducted at the University of Oregon. Families were recruited from the local community, and children were first brought into the laboratory at 7 to 9 months of age, returning at 18 to 21 months, and again at 3 to 4 years of age. These assessments are referred to as the time 1 , time 2 , and time 3 assessments, respectively. Methods and data reported here are from the time 2 and time 3 assessments. Other aspects of the time 1 and time 2 assessments have been reported in previous publications $[13,15]$. The current analyses relied on a sample of children with both genotyping and parent interaction assessments at time 2 and complete temperament data at time 3. A total of 52 participants met these criteria ( 32 males; additional information about sample characteristics and recruitment can be found in [15]).

\subsection{Measures}

2.2.1. Temperament. At time 2, caregivers had completed the early childhood behavior questionnaire (ECBQ; [16]). Subscales from this measure were aggregated to form an SS measure (comprised of activity level, high-intensity pleasure, and impulsivity) and an EC measure (comprised of attentional focusing, attentional shifting, and inhibitory control).

At time 3, parents were asked to complete the children's behavior questionnaire (CBQ; [17]). The CBQ is designed for older children; while it is similar to the ECBQ, the subscales are not identical. Attention shifting is not present in the $\mathrm{CBQ}$, so our time $3 \mathrm{EC}$ aggregate $(\alpha=.73)$ consisted of attentional focusing and inhibitory control. Our time 3 SS scale $(\alpha=.74)$ was the same as the time 2 measure, constructed from the CBQ versions of activity level, high-intensity pleasure and impulsivity. In addition, we constructed a measure of Negative Affect $(\alpha=.66)$ from the CBQ subscales for Sadness and Fear. Negative Affect is an important component of temperament, and although we did not expect it to be predicted by DRD4 or a DRD4 $x$ parenting interaction, we included it in the analyses to provide a contrast with SS and EC outcomes.

2.2.2. Parent-Toddler Interaction. Parenting quality was assessed at time 2 using a videotaped free-play procedure and a rating scheme adapted from the NICHD Study of Early Child Care (1993; reported previously in [3]). The parent (mostly the mother) was asked to play with the child for 10 minutes in a laboratory room that contained only toys and an area rug. This interaction was videotaped and subsequently rated. Raters watched the entire interaction and then used 7-point Likert scales to rate the parent on the following items (see [15] for additional details): (1) Supportive Presence (positive regard and emotional support), (2) Respect for Autonomy (unobtrusive in interactions with child), (3) Stimulation of Cognitive Development (directed instruction, teaching), (4) Hostility (anger, rejection, and negative regard), and (5) Confidence (confidence shown in interactions with child). Twenty videos (44\%) were coded twice to assess inter-rater reliability. Inter-rater reliability was adequate $(r=.76)$. Hostility was reversed, and ratings on these five items were aggregated into a single parenting quality measure $(\alpha=.81)$.

2.2.3. Genotyping. Genomic DNA was prepared from buccal cell samples taken from each child at time 2 using QuickExtract DNA extraction solution (Epicentre Biotechnologies, Madison, WI). The DRD4 variable number tandem repeat (VNTR) polymorphism was amplified using $0.2 \mu \mathrm{M}$ of each primer DRD4F 5'-GCGACTACGTGGTCTACTCG and DRD4R 5'-AGGACCCTCATGGCCTTG in a mixture containing $8 \%$ DMSO, $200 \mu \mathrm{M}$ each dNTP, $2.5 \mathrm{mM} \mathrm{MgCl}_{2}$, 1x $\left(\mathrm{NH}_{4}\right)_{2} \mathrm{SO}_{4}$ buffer along with 2.5 units recombinant 
TABLE 1: Descriptive statistics and correlations.

\begin{tabular}{|c|c|c|c|c|c|c|}
\hline & \multirow[b]{2}{*}{ M } & \multirow[b]{2}{*}{$\mathrm{SD}$} & \multicolumn{4}{|c|}{ Correlations } \\
\hline & & & $(1)$ & $(2)$ & (3) & (4) \\
\hline \multicolumn{7}{|c|}{ Time 2 - parenting observation } \\
\hline (1) Parenting quality & 5.21 & .88 & 1.00 & & & \\
\hline \multicolumn{7}{|c|}{ Time 3 - CBQ temperament scales } \\
\hline (2) Sensation seeking & 4.86 & .79 & .00 & 1.00 & & \\
\hline (3) Effortful control & 4.79 & .90 & -.02 & $-.61^{*}$ & 1.00 & \\
\hline (4) Negative affect & 3.87 & .84 & .03 & $-.33^{*}$ & .10 & 1.00 \\
\hline
\end{tabular}

* Denotes $P<0.05$.

TABLE 2: Summary of regression models.

\begin{tabular}{|c|c|c|c|}
\hline \multirow[b]{2}{*}{ Dependent variables } & \multicolumn{3}{|c|}{ Time 3 - CBQ temperament scales } \\
\hline & Sensation Seeking & Effortful Control & Negative Affect \\
\hline \multicolumn{4}{|l|}{ Step 1} \\
\hline Adjusted $R$ square & -.03 & -.04 & -.03 \\
\hline Degrees of freedom & 2,49 & 2,49 & 2,49 \\
\hline Sig. $F$ change & .71 & .87 & .70 \\
\hline \multicolumn{4}{|l|}{ Sex of child } \\
\hline Standardized beta & -.04 & -.05 & -.04 \\
\hline Significance & .80 & .71 & .81 \\
\hline \multicolumn{4}{|l|}{ Age of child at T3 } \\
\hline Standardized beta & .11 & .05 & -.12 \\
\hline Significance & .44 & .71 & .42 \\
\hline \multicolumn{4}{|l|}{ Step 2} \\
\hline Adjusted $R$ square & -.01 & -.05 & -.02 \\
\hline Degrees of freedom & 2,47 & 2,47 & 2,47 \\
\hline Sig. $F$ change & .29 & .57 & .32 \\
\hline \multicolumn{4}{|l|}{ DRD4 7-repeat status } \\
\hline Standardized beta & -.20 & .14 & .22 \\
\hline Significance & .16 & .33 & .14 \\
\hline \multicolumn{4}{|l|}{ Parenting quality } \\
\hline Standardized beta & .10 & .07 & .03 \\
\hline Significance & .51 & .65 & .83 \\
\hline \multicolumn{4}{|l|}{ Step 3} \\
\hline Adjusted $R$ square & -.02 & .08 & -.04 \\
\hline Degrees of freedom & 1,46 & 1,46 & 1,46 \\
\hline Sig. $F$ change & .44 & $.008^{*}$ & .66 \\
\hline \multicolumn{4}{|c|}{ DRD4 7-R X parenting quality } \\
\hline Standardized beta & -.14 & .47 & .08 \\
\hline Significance & .44 & $.008^{*}$ & .66 \\
\hline
\end{tabular}

* Denotes $P<0.05$.

Taq polymerase (Fermentas Inc., Glen Burnie, MD), and approximately $20 \mathrm{ng}$ genomic DNA in a volume of $25 \mu \mathrm{L}$. The samples were heated in a PTC-200 or 225 thermocycler (MJ Research) at $95^{\circ} \mathrm{C} 3 \mathrm{~min}$ and then cycled 40 times at $95^{\circ} \mathrm{C}$ $20 \mathrm{sec}, 57^{\circ} \mathrm{C} 20 \mathrm{sec}$, and $72^{\circ} \mathrm{C} 1 \mathrm{~min}$, followed by another $72^{\circ} \mathrm{C} 3 \mathrm{~min}$. The products were separated and visualized on a $2 \%$ agarose gel (type $1-A$, Sigma-Aldrich Corp., St. Louis, MO) stained with ethidium bromide.

Based on the genotyping procedure, children were divided into either the 7 -repeat present group (individuals with 1 or 2 copies of the 7 -repeat allele; $N=18$ ) and the 7 repeat absent group (individuals with no 7-repeat alleles; $N$ $=34$ ).

\section{Results}

Descriptive statistics and correlations are presented in Table 1. Separate hierarchical regressions were conducted using a dummy-coded DRD4 variable (7-repeat present versus 7 -repeat absent) and parenting quality at time 2 
(continuous, centered) as predictors, sex of child and age of child at time 3 as covariates, and CBQ SS, Negative Affect, and $\mathrm{EC}$ at time 3 as dependent variables. Covariates were entered simultaneously on the first step of the regression, predictors on the second step, and an interaction term (DRD4 status $\times$ parenting quality) on the third step. Regression results are presented in Table 2.

At time 3, there was no evidence of significant DRD4 $\times$ Parenting quality interaction predicting either SS or Negative Affect. There was, however, a significant interaction predicting EC. This interaction is plotted in Figure 1. The interaction was probed by examining simple slopes. Analyses showed that the association between parenting quality and EC was significant for children with the 7-repeat present, $\beta$ $=0.57, \mathrm{t}(46)=2.46, P=0.02$, but not for children with the 7 -repeat absent, $\beta=-0.21, \mathrm{t}(46)=-1.19, P=0.24$.

\section{Discussion}

We found a significant $G \times E$ interaction indicating that parenting quality was positively associated with EC in the presence, but not the absence, of the DRD4 7-repeat allele. This was the relationship we had failed to find at the age of 18 to 21 months, but now it seems to be present in children at 3 to 4 years of age. It should be noted, however, that due to the small sample size and the novelty of the results, these findings should be treated with caution and considered preliminary until they are replicated in an independent sample. Additionally, since the results are preliminary, the discussion that follows is speculative.

The observed interaction may provide a possible mechanism by which the DRD4 7-repeat allele interacts with environmental influences. EC as measured in childhood has been repeatedly found to correlate with the child's ability to resolve conflict during cognitive tasks $[6,18]$. The ability to resolve conflict is a central function of the executive attention network involving the anterior cingulate cortex (ACC), anterior insula, and basal ganglia [6]. Adult imaging data shows that variations in DRD4 are associated with variations in the efficiency of resolving conflict in the Attention Network Test (ANT) and ACC activation during ANT performance [19].

Recently, we argued that control mechanisms shift during early childhood [11, 12]. This conclusion was based in part on resting state imaging data showing that the long connections linking the ACC to distant brain areas develop slowly over childhood [14]. Early in development, the orienting and executive networks are more integrated, while later in development, they are quite separate anatomically. These imaging data agree with behavioral results showing that in infancy and early childhood control seems to involve orienting and that only at about 4 years of age is there some emotional and cognitive control by the executive attention network [11]. The late developing connectivity of the executive network could explain why we see no evidence that DRD4 relates to EC in 18- to 21-month-old children, since executive attention does not yet exercise control of relevant behaviors. However, we do find such a relationship

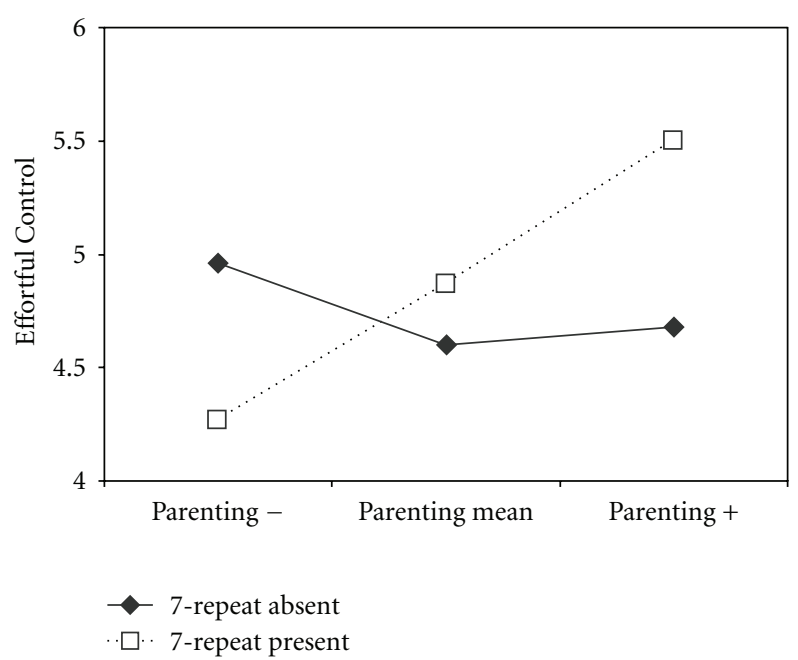

FIGURE 1: Gene by environment interaction showing EC ratings as a function of quality of parenting and the presence or absence of the 7-repeat allele of the DRD4 gene. Parenting quality is a continuous variable in the analyses. The shape of this interaction is illustrated here using the overall mean, parenting below the 25th percentile (lower-quality parenting) and parenting above the 75th percentile (higher-quality parenting).

at 4 years when the executive attention network is more fully connected. It is also consistent with evidence that the presence of the DRD4 7-repeat is associated with less sustained orienting of attention during infancy [3].

How could the executive network be influenced by parenting, peers, and other diverse environmental factors? The DRD4 gene encodes a dopamine receptor, and the 7-repeat allele is associated with reduced expression $[20,21]$ and an altered response to dopamine $[22,23]$, which is a major neuromodulator of the ACC. The ACC is clearly involved in the brain's reward and punishment pathways [6]. Changes in its functioning due to differences in receptor-mediated signal transduction could influence responses to dopamine and thus the impact of reward and punishment. Reward and punishment are important means of parental influence. The strength of self-control developed in childhood could continue to affect the influence of peers in adolescence and young adulthood.

On the other hand, in this study, we did not find the $\mathrm{G} \times \mathrm{E}$ interaction relating the presence of the DRD4 gene and parenting to SS that was found earlier. However, there was a significant negative correlation between EC and SS, perhaps indicating that by this age, the executive attention system related to EC serves to regulate behaviors relating to SS. These findings could reflect developmental changes in control mechanisms that take place between 18 months and 4 years.

Our conceptualization of the DRD4 gene and the development of the executive network has broad implications for studying self-regulation and associated difficulties such as attention deficit hyperactivity disorder (ADHD). Recent studies of ADHD children using the Attention Network Test have shown abnormalities in the alerting and executive 
networks [24]. Halperin and Shulz [25] have argued that ADHD begins with a deficit in alerting and only later results in a deficit in the executive attention network. However, when children with ADHD were compared to typically developing children in attention tasks, those children with the 7-repeat allele were normal, while those without the 7 -repeat showed poorer performance in most attention tests [26]. The frequent finding of increased variability of attention in children with ADHD may reflect their susceptibility to environmental influence, particularly during the time executive attention connectivity is developing [14].

If the DRD4 gene is moderating the influence of socialization practices, then we might expect that associations between the 7-repeat and phenotypic outcomes will change as the child develops, and the focus of parenting efforts is altered to meet new challenges. There is considerable development of EC between 2 and 4 years of age $[18,27,28]$. High-quality parenting at 18 to 21 months of age may be more reflective of parents' role in managing children's exuberant behavior rather than influencing EC. In support of this idea is the negative correlation between EC and SS at Time 3. At 2 years of age, the parental influence on SS was seen in the form of a $\mathrm{G} \times \mathrm{E}$ interaction, while by age 4 , it was seen in the form of a negative relation between SS and EC. This finding agrees with the increasing control that executive attention exerts in later childhood.

Intervention studies have attempted to examine how individual differences, including genetic variation, influence early child development $[29,30]$. For example, Kegel et al. found that children with the 7-repeat allele specifically benefited from positive feedback during early literacy training, but did worse than those without the 7-repeat when positive feedback was absent. A recent commentary argues for the general advantage of using such interventions for testing proposed gene $\times$ environment interactions, in part because they allow children to be randomized to conditions [31].

EC and executive attention $[6,18]$ provide a framework for understanding the causes of the diverse behavioral effects found during early childhood. The sample size of our current data set is small, so we must consider the current findings with caution. However, our previous paper at the age of 18 to 21 months concluded that executive attention was not involved in the $\mathrm{G} \times \mathrm{E}$ interaction, so this paper is important in pointing out the potential developmental limitation of the previous result. Moreover, the multiple replications of the DRD4 by environment interaction make it more important to understand the basic mechanism(s) of this interaction. Future research needs to move further toward an understanding of how this genetic variation affects the brain, resulting in a range of behaviors, and how we can use interventions with random assignment as a vehicle to better understand this $\mathrm{G} \times \mathrm{E}$ interaction.

\section{Conclusions}

At the age of 18 to 21 months, a $\mathrm{G} \times \mathrm{E}$ interaction was not found for children's EC as measured by questionnaire. However, in this paper, we report that parenting quality interacts with the presence of the 7-repeat allele to determine EC in 3-4-year-old children. The change between 21 months and 3-4 years may reflect the increased connectivity and separation of the executive network in older children and adults. However, due to the small sample size and the novelty of the results, these findings should be treated with caution and considered preliminary until they are replicated in an independent sample.

\section{Authors' Contribution}

B. E. Sheese ran the study, analyzed the data, and wrote a first draft of the paper; M. I. Posner and M. K. Rothbart conceived and designed the study and rewrote the paper; P. M. Voelker performed the genotyping, helped with the genetic analysis, and helped write the paper.

\section{Acknowledgments}

This paper was supported by NICHD Grant HD 060653 to Georgia State University and by an Illinois Wesleyan University ASD grant to the first author.

\section{References}

[1] M. J. Bakermans-Kranenburg and M. H. van Ijzendoorn, "Gene-environment interaction of the dopamine D4 receptor (DRD4) and observed maternal insensitivity predicting externalizing behavior in preschoolers," Developmental Psychobiology, vol. 48, no. 5, pp. 406-409, 2006.

[2] A. Knafo, S. Israel, and R. P. Ebstein, "Heritability of children's prosocial behavior and differential susceptibility to parenting by variation in the dopamine receptor D4 gene," Development and Psychopathology, vol. 23, no. 1, pp. 53-67, 2011.

[3] B. E. Sheese, P. M. Voelker, M. K. Rothbart, and M. I. Posner, "Parenting quality interacts with genetic variation in dopamine receptor D4 to influence temperament in early childhood," Development and Psychopathology, vol. 19, no. 4, pp. 1039-1046, 2007.

[4] R. P. Ebstein, O. Novick, R. Umansky et al., "Dopamine D4 receptor (D4DR) exon III polymorphism associated with the human personality trait of novelty seeking," Nature Genetics, vol. 12, no. 1, pp. 78-80, 1996.

[5] H. Larsen, C. S. van der Zwaluw, G. Overbeek, I. Granic, B. Franke, and R. C. M. E. Engels, "A variable-number-oftandem-repeats polymorphism in the dopamine D4 receptor gene affects social adaptation of alcohol use: investigation of a gene-environment interaction," Psychological Science, vol. 21, no. 8, pp. 1064-1068, 2010.

[6] M. I. Posner, M. K. Rothbart, B. E. Sheese, and Y. Tang, "The anterior cingulate gyrus and the mechanism of selfregulation," Cognitive, Affective and Behavioral Neuroscience, vol. 7, no. 4, pp. 391-395, 2007.

[7] J. Belsky and M. Pluess, "Beyond diathesis stress: differential susceptibility to environmental stress," Psychological Bulletin, vol. 135, no. 6, pp. 885-908, 2009.

[8] M. J. Bakermans-Kranenburg and M. H. Van Ijzendoorn, "Differential susceptibility to rearing environment depending on dopamine-related genes: New evidence and a metaanalysis," Development and Psychopathology, vol. 23, no. 1, pp. 39-52, 2011. 
[9] Y. C. Ding, H. C. Chi, D. L. Grady et al., "Evidence of positive selection acting at the human dopamine receptor D4 gene locus," Proceedings of the National Academy of Sciences of the United States of America, vol. 99, no. 1, pp. 309-314, 2002.

[10] J. E. Settle, C. T. Dawes, N. A. Christakis, and J. H. Fowler, "Friendships moderate an association between a dopamine gene variant and political ideology," Journal of Politics, vol. 72, no. 4, pp. 1189-1198, 2010.

[11] M. I. Posner, M. K. Rothbart, B. E. Sheese, and P. Voelker, "Control networks and neuromodulators in early development," Developmental Psychology, vol. 48, no. 3, pp. 827-835, 2012.

[12] M. K. Rothbart, B. E. Sheese, M. R. Rueda, and M. I. Posner, "Developing mechanisms of self-regulation in early life," Emotion Review, vol. 3, no. 2, pp. 207-213, 2011.

[13] B. E. Sheese, P. Voelker, M. I. Posner, and M. K. Rothbart, "Genetic variation influences on the early development of reactive emotions and their regulation by attention," Cognitive Neuropsychiatry, vol. 14, no. 4-5, pp. 332-355, 2009.

[14] D. A. Fair, A. L. Cohen, J. D. Power et al., "Functional brain networks develop from a "local to distributed" organization," PLoS Computational Biology, vol. 5, no. 5, Article ID e1000381, 2009.

[15] B. E. Sheese, M. K. Rothbart, M. I. Posner, L. K. White, and S. H. Fraundorf, "Executive attention and self-regulation in infancy," Infant Behavior and Development, vol. 31, no. 3, pp. 501-510, 2008.

[16] S. P. Putnam, M. A. Gartstein, and M. K. Rothbart, "Measurement of fine-grained aspects of toddler temperament: the early childhood behavior questionnaire," Infant Behavior and Development, vol. 29, no. 3, pp. 386-401, 2006.

[17] M. K. Rothbart, S. A. Ahadi, K. L. Hershey, and P. Fisher, "Investigations of temperament at three to seven years: the children's behavior questionnaire," Child Development, vol. 72, no. 5, pp. 1394-1408, 2001.

[18] M. K. Rothbart, Becoming who we are: Temperament, Personality and Development, Guilford Press, New York, NY, USA, 2011.

[19] J. Fan, J. Fossella, T. Sommer, Y. Wu, and M. I. Posner, "Mapping the genetic variation of executive attention onto brain activity," Proceedings of the National Academy of Sciences of the United States of America, vol. 100, no. 12, pp. 7406-7411, 2003.

[20] O. Schoots and H. H. M. Van Tol, "The human dopamine D4 receptor repeat sequences modulate expression," Pharmacogenomics Journal, vol. 3, no. 6, pp. 343-348, 2003.

[21] J. Simpson, G. Vetuz, M. Wilson, K. J. Brookes, and L. Kent, "The DRD4 receptor exon 3 VNTR and 5' SNP variants and mRNA expression in human post-mortem brain tissue," American Journal of Medical Genetics B, vol. 153, no. 6, pp. 1228-1233, 2010.

[22] V. Asghari, S. Sanyal, S. Buchwaldt, A. Paterson, V. Jovanovic, and H. H. M. Van Tol, "Modulation of intracellular cyclic AMP levels by different human dopamine D4 receptor variants," Journal of Neurochemistry, vol. 65, no. 3, pp. 1157-1165, 1995.

[23] C. Wedemeyer, J. D. Goutman, M. E. Avale, L. F. Franchini, M. Rubinstein, and D. J. Calvo, "Functional activation by central monoamines of human dopamine D4 receptor polymorphic variants coupled to GIRK channels in Xenopus oocytes," European Journal of Pharmacology, vol. 562, no. 3, pp. 165$173,2007$.

[24] K. A. Johnson, I. H. Robertson, E. Barry et al., "Impaired conflict resolution and alerting in children with ADHD: evidence from the Attention Network Task (ANT)," Journal of child psychology and psychiatry, and allied disciplines, vol. 49, no. 12, pp. 1339-1347, 2008.

[25] J. M. Halperin and K. P. Schulz, "Revisiting the role of the prefrontal cortex in the pathophysiology of attentiondeficit/hyperactivity disorder," Psychological Bulletin, vol. 132, no. 4, pp. 560-581, 2006.

[26] J. Swanson, J. Oosterlaan, M. Murias et al., "Attention deficit/hyperactivity disorder children with a 7-repeat allele of the dopamine receptor D4 gene have extreme behavior but normal performance on critical neuropsychological tests of attention," Proceedings of the National Academy of Sciences of the United States of America, vol. 97, no. 9, pp. 4754-4759, 2000.

[27] G. Kochanska, "Multiple pathways to conscience for children with different temperaments: from toddlerhood to age 5," Developmental psychology, vol. 33, no. 2, pp. 228-240, 1997.

[28] M. K. Rothbart and M. R. Rueda, "The development of effortful control," in Developing Individuality in the Human Brain: A Tribute to Michael I. Posner, U. Mayr, E. Awh, and S. W. Keele, Eds., pp. 167-188, American Psychological Association, Washington, DC, USA, 2005.

[29] M. R. Rueda, M. K. Rothbart, B. D. McCandliss, L. Saccomanno, and M. I. Posner, "Training, maturation, and genetic influences on the development of executive attention," Proceedings of the National Academy of Sciences of the United States of America, vol. 102, no. 41, pp. 14931-14936, 2005.

[30] C. A. T. Kegel, A. G. Bus, and M. H. van Ijzendoorn, "Differential susceptibility in early literacy instruction through computer games: the role of the Dopamine D4 Receptor Gene (DRD4)," Mind, Brain, and Education, vol. 5, no. 2, pp. 71-78, 2011.

[31] M. H. van Ijzendoorn, M. J. Bakermans-Kranenburg, J. Belsky et al., "Gene by environment experiments: a new approach to find missing heritability," Nature Reviews Genetics, vol. 12, article 881, 2011. 


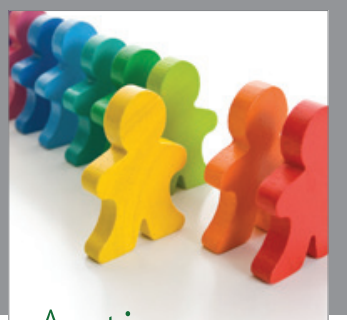

Autism

Research and Treatment
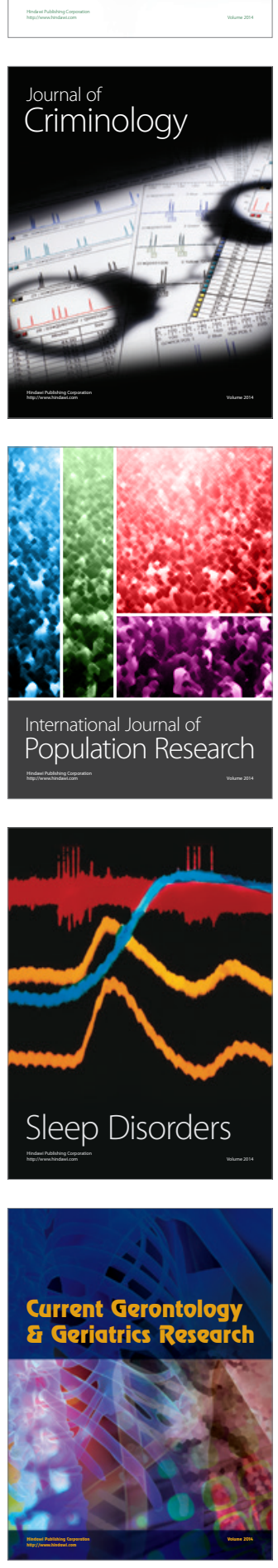
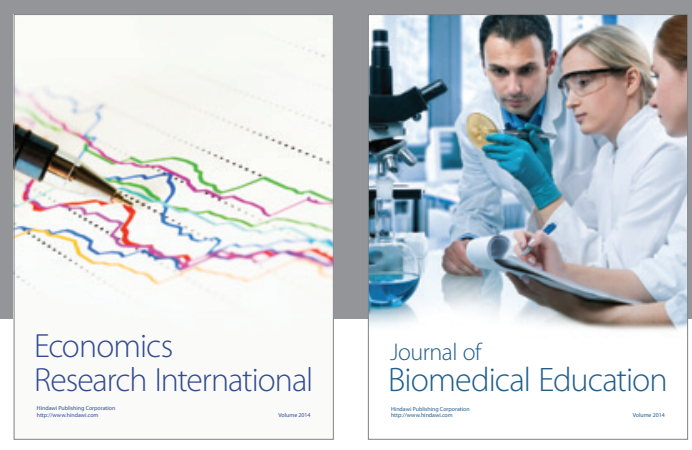

Journal of

Biomedical Education

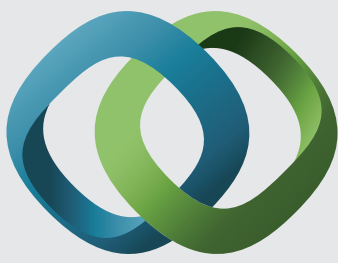

\section{Hindawi}

Submit your manuscripts at

http://www.hindawi.com
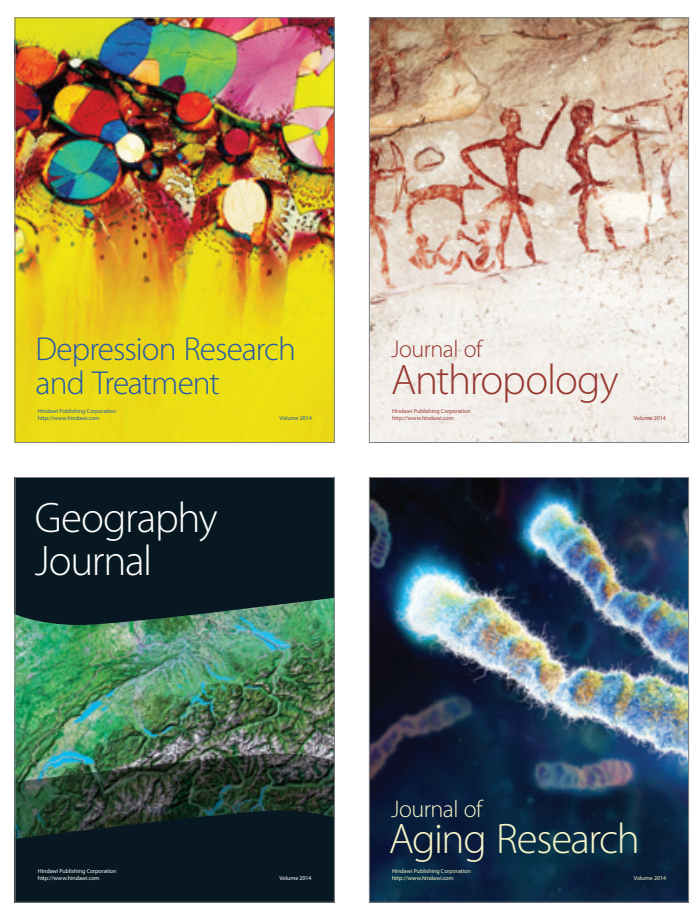

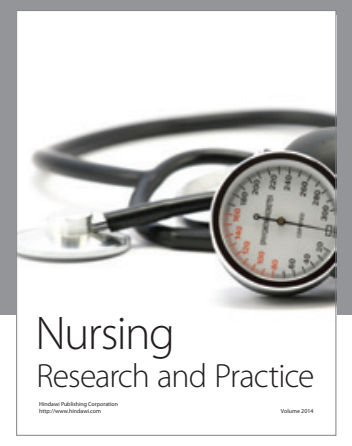

Nursing

Research and Practice

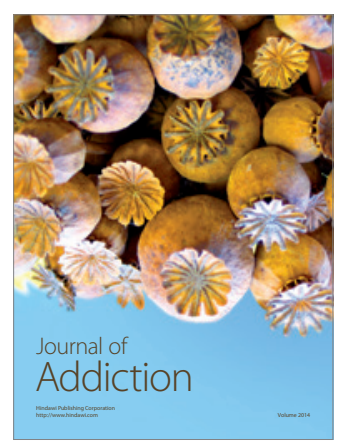

Child Development

Research

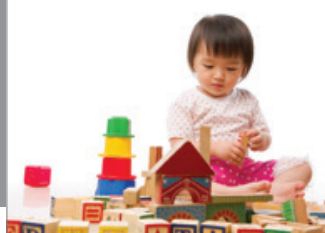

迥
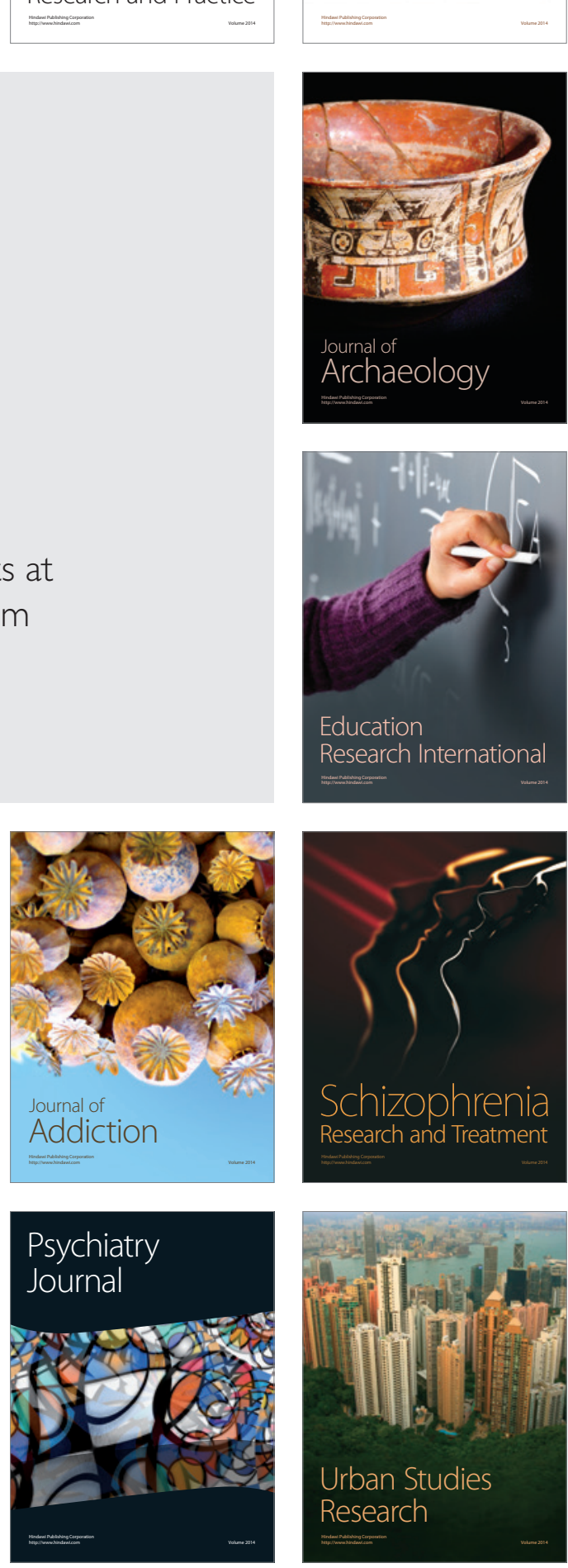